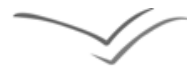 \\ VERSITA
}

DOI 10.2478/jped-2013-0001

JoP 4 (1): $5-10$

\section{Shades of Freire: Exorcising the spectre haunting pedagogy}

\section{Andrew Wilkins}

Abstract : In the second part of this special issue on neoliberalism, pedagogy and curriculum, I explore the contributions of each author to confronting neo-liberal reforms of education, notably the spectre of neo-liberalism haunting aspects of pedagogy, teaching and curriculum. Exemplary of the scholarly work produced by many critical educators, the contributing authors share an understanding of the oppressive function of educational apparatuses and their complicity with the reproduction of dominant epistemes of knowledge/power. In this case, neo-liberalism is defined as a canonical narrative through which existing education relations, practices and discourses are structured and mediated. Against this neo-liberal imaginary, the authors argue in favour of models of knowing, learning and teaching that work to sustain practices of critical inquiry and self-discovery among learners as active, reflexive and engaged subjects. The result is a timely collection of papers critiquing the nuances pertaining to the global transmission of neo-liberal education and a much-needed reinvigoration of the Freirean demand for a liberating and critical pedagogy.

Key words: pedagogy, curriculum, neoliberalism, policy, democracy, politics

\section{Pedagogy as Social Practice}

Much has been written about the alienating and authoritarian character of education since Paulo Freire (1996 [1968]) highlighted the symbolic violence committed through education institutions seeking to mirror rather than challenge dominant cultural and political ideations. Education institutions, he observed, provisionally maintain the legitimacy of their hegemony through the rigid application of a didactic, disciplinary order. Such an order is achieved and maintained through the subordination of learners to the authority of teachers. One implication of this is that teachers depend on the obedience of learners in order to retain and exercise the impression of power and authority ascribed to their role. (This is evocative of the Hegelian 
master-slave dialectic in which one subject invariably depends on the other as a condition of their positioning and self-knowing). Conversely, if learners wish to be recognised and validated they must dutifully comply with these socially ascribed roles. This means that education institutions can hope to retain the legitimate right to impose unequal power relations (e.g. the master-slave dialectic) and adjudicate the validity of such relations inasmuch as learners seek validation from such systems. This can seriously hamper and restrict the capacity and willingness of learners to resist the hegemony of education to the extent they wish to recognised and affirmed as 'included' rather than 'excluded'. Compliance demands obligation and obligation begets reward.

Freire (1996 [1968]) further noted how education systems provisionally secure cultural, linguistic and political dominance through pedagogy (the art or science of teaching). For Freire, the oppressive function of education reveals itself through the norms and customs framing pedagogy, e.g. teachers are revered as infallible and all-knowing in contrast to learners who are positioned as subordinate and passive. Pedagogy in other words constitutes a social relation, a form of sociality and a modality for the exercise and legitimation of the teacher-learner (master-slave) dialectic. Left unchecked or scrupulously examined, pedagogy thus works to undermine the creative input of learners, especially in the way some learners are expected to 'engage' with systems of knowledge. This is especially true of many contemporary education systems where the role of learners is limited to the adoption and memorisation (recall) of received or privileged knowledge. A corollary of this is that learners are reduced to passive recipients of knowledge transfer, in effect denied agency as cultural and historical agents with experiences and insights from which new knowledge might be gleaned or existing knowledge might be tested and scrutinised. When designed to be delivered in this way, knowledge is conveniently parcelled into self-contained units or items which can be transferred or deposited into learners - what Freire famously referred to as the 'banking' model (1996) - with the result that a critical space for dialogue, debate and deliberation between teachers and learners is almost certainly eclipsed or frustrated.

The mission for many critical educators, and those contributing authors to this special issue, therefore centres on efforts to displace any model of pedagogy which exacerbates the efforts of learners to imagine, to hope and to aspire as creative and critical agents. The lesson here being that learners can only come to appreciate the empowering and transformative effects of knowledge through playing an active role in the struggle to define and validate its application and utility in the world. 


\section{Curricula as Neo-liberal Pedagogy}

Giroux, a cultural theorist and exponent of 'critical pedagogy', relays a similar set of concerns when he aligns the US ideological state apparatus to a media-military composition that is corporate and anti-statist in scope. The distorting, ideological effects of this assemblage, he argues, is that mediations and formations of public discourse, public institutions and public space become saturated by a "dominant public pedagogy with its narrow and imposed schemes of classification and limited modes of identification [that] use[s] the educational force of the culture to negate the basic conditions for critical agency" (2004, p. 106). Pedagogy therefore works to provisionally stabilise the always unsettled and unfinished character of identity formations through the availability of manufactured, ready-made categories and authorised discourses. From this perspective, pedagogy can be understood to constitute a set of social and political relations that "connects the apparently self-contained act of teaching with culture, structure and the mechanisms of social control" (Alexander, 2008, p. 3). As Bernstein (1999) further observes, "pedagogy is a sustained process whereby somebody(s) acquires a new form or develops existing forms of conduct, knowledge, practice and criteria from somebody (s) or something deemed to be an appropriate provider and evaluator" (p. 148).

The scope and content of school curricula is also marked by power relations. This is best reflected in the contested field of education policy making. Take for example the combined efforts of British senior government officials, media pundits, policy makers and academics to classify and legitimate what types of knowledge and scientific practices and discourses should be taught and in some circumstances made compulsory through schools. It is an ideological battlefield. Far from being neutral, random or even unbiased, the content and design of school curricula is powerfully shaped by the prevailing cultural and political sensibilities of a given society. More importantly, national prescriptions for education policy implementation and development are governed and sometimes impeded by transnational trends including the needs of labour markets and the global economy.

Government policy and rhetoric in England over the last thirty years confirms this. The most important task of 'governing' in England during this period has been to communicate and rationalize the benefits of 'entrepreneurialism' and 'enterprise' to young people, wider society and the economy, for example (see Wilkins, 2012a). Mccafferty (2010) labels this trend or movement 'neo-liberal pedagogy'. It refers to "the inculcation of enterprise values as a crucial element of contractual and pedagogic obligation" (p. 542). Pedagogic obligations and duties of this kind can be traced to the ways in which 
schools in England are governed and made governable through the circulation of business and enterprise norms including competition, flexibility, innovation and efficiency. Value systems such as these are relayed through the battery of formal and informal networks of organisations and constituencies charged with the authority of managing and steering policy implementation and development at the local level. The content of school curricula therefore is sometimes constructed and rationalized on the basis of its contribution to the economy and the edifice of market discourses and practices.

As Hill (2007) observes, schools as well as higher education institutions are complicit in producing "compliant, ideologically indoctrinated, pro-capitalist, effective workers" (p. 120) to the extent that these institutions are forced to frame the value of education in narrow economic, managerial and market terms. The spectre of the market that haunts educational practices of pedagogy and curriculum is therefore both real and elusive - we know it exists but also recognise its mutating character and capacity to co-habit with or co-opt traditional social democratic trends. The timely nature of the second part of this special issue on neoliberalism, pedagogy and curriculum issue is that the authors seek to trace the coordinates of this spectre and uncover its mutating, potentially deleterious effects.

Each of the authors is meticulous and rigorous in capturing some of nuances and dynamics pertaining to neo-liberal pedagogy in their respective countries and concomitant education systems. These insights attend to some of the complexities of expressions and mediations of neo-liberal pedagogy within national and regional policy contexts, thus revisiting ideas of "context", "articulation" and "co-habitation" emphasised in part 1 of this special issue (see Wilkins, 2012b). Specifically, each author offers up a set concrete examples for identifying the interconnection of neo-liberal and pedagogical forces. More ambitiously, they engage with the uneasy relationship between neo-liberal and democratic trends and utilise an important set of theoretical and methodological frameworks, toolboxes and algorithms for imagining and actualising socially just and progressive visions of education reform.

\section{Mapping Global Trends in 'Neo-liberalisation'}

In the first of these articles Wanberg explores the seeming disjuncture between neo-liberal pedagogy and critical pedagogy. He presents the case of a school district in the US state of Arizona where local officials have issued a ban on schools using Freire's classic text Pedagogy of the Oppressed. For Wanberg, these efforts to outlaw certain literatures signal a 'state-wide proscription of ethic studies', one that seeks to generate neutrality through an appeal to market-based ideas of freedom, autonomy and self-determination. 
An insidious effect of such efforts, Wanberg notes, is the creation of further misrecognition of actually existing inequalities and prejudices stemming from cultural difference, 'race' and ethnicity. The following article investigates the formal and implicit racial logic inscribed in discourses of 'management' (from the plantation to the corporation) and traces the circulation of these ideas within aspects of contemporary US schooling. The authors, Casey, Lozenski and McManimon, contend that neo-liberal pedagogy in the US cannot and should not be considered separate from the spectre of 'race' that haunts management; rather, they can be viewed as closely intertwined and reproduced through each other.

The emphasis of Rodriguez's article marks a shift from the US to the Spanish context. Rodriguez highlights the role of child-centred pedagogies in the reform of the Spanish curriculum during the Socialist administration of the late 1980 s/early 1990 s and draws attention to its close approximation to and celebration of neo-liberal ideations of individual freedom and autonomy. Rodriguez ponders the progressive nature of these reforms, especially their conservative, neo-liberal guise, and explores their lack of compatibility with democratic notions of social justice and equity. In the following article Harris draws on a case study of a group of students at a Sudanese Australian high school in Melbourne to interrogate the application of visual methods for engendering forms of critical pedagogy and 'common sense' thinking around schooling and otherness. Harris' reflexive account of using visual-based research methods is particularly pertinent. She demonstrates the utility of this approach for tracing the material, affective and spatial framings through which neo-liberal education processes crowd out marginal voices. More instructively and precisely, she highlights the utility of these methods in generating forms of critical pedagogy that privilege intercultural communication and translation.

To demonstrate the interconnections between neo-liberalism, corporate philanthropy and teacher training programmes, Price and McConney investigate the explicit agenda underpinning Teach For All (TFA) programmes made available worldwide. Price and McConney trace the meanings and practices ascribed to 'good teaching' through these programmes and draw attention to their neo-liberal colouration. Specifically, they highlight the ways in which the emergence of a manufactured 'crisis' in teaching offers up unique opportunities for private investment and corporate takeover in areas formerly government sanctioned. In the final article Echeverria and Hannam engage with some of the conceptual strategies made available through the framework of 'Community of Philosophical Inquiry' and elaborate on its application as a method for advancing better forms of democratic praxis in the classroom and empowering learners to think creatively, morally and 
reflexively. Presented as a counter-narrative to neo-liberal pedagogy, Echeverria and Hannam emphasise the enabling, empowering effects of a dialogical approach to teaching and learning, one that aims to generate spaces for debate and deliberation between teachers and learners as co-producers of knowledge.

\section{References}

Alexander, R. (2008). Pedagogy, Culture and Curriculum. In P. Murphy, J. Soler, $\&$ K. Hall (eds.) Pedagogy and Practice: Culture and Identities. (pp. 3-27). The Open University: Milton Keynes

Bernstein, B. (1999). Official knowledge and pedagogic identities. In F.Christie (ed.) Pedagogy and the Shaping of Consciousness. Continuum: London

Freire, P. (1996 [1968]). Pedagogy of the Oppressed. Translated by Myra Bergman Ramos. Penguin: London

Giroux, H. (2004). The Terror of Neoliberalism. Authoritarianism and the Eclipse of Democracy. Paradigm: Colorado

Hill, D. (2007). Neoliberalism and the perversion of education. In E.W. Ross, \& R. Gibson (eds.) Neoliberalism and education reform. (pp. 107-144). Cresskill, NJ: Hampton Press

Mccafferty, P. (2010). Forging a 'neoliberal pedagogy': The 'enterprising education' agenda in schools. Critical Social Policy, 30 (4), 541-563.

Wilkins, A. (2012a) Push and pull in the classroom: Gender, competition and the neoliberal subject. Gender and Education, 24 (7), 765-768.

Wilkins, A. (2012b) Pedagogy of the Consumer: The Politics of Neo-liberal Welfare Reform. Journal of Pedagogy. Special issue: Neo-liberalism, Pedagogy and Curriculum: A Global Perspective I, 3(2), 161-173.

\section{Author:}

Andrew Wilkins, Ph.D., Assistant Professor

Roehampton University

Department of Education

Roehampton Lane

London

SW15 5PU

UK

email: andrew.wilkins@roehampton.ac.uk 